\title{
CONSERVADORISMO CONTÁBIL NAS COMPANHIAS ABERTAS E FECHADAS BRASILEIRAS
}

ACCOUNTING CONSERVATISM IN BRAZILIAN PUBLICLY-QUOTED AND PRIVATE COMPANIES

\begin{abstract}
RESUMO
Objetiva-se neste artigo identificar a existência de diferenças significativas entre companhias abertas e fechadas brasileiras no nível de conservadorismo de suas demonstrações contábeis. A pesquisa, do tipo exploratória e descritiva, baseia-se em amostra composta por 1.384 empresas-ano, sendo 770 observações referentes a companhias fechadas e 614 a companhias abertas, no período de 2000 a 2004. Utilizou-se o modelo de Ball e Shivakumar (2005) que permite analisar o nível de conservadorismo por meio da reversão dos resultados contábeis. Os resultados obtidos evidenciam que as companhias fechadas apresentam menor probabilidade de reconhecimento oportuno das perdas e, por isso, possuem menor nível de conservadorismo nas demonstrações contábeis em relação às companhias abertas.
\end{abstract}

\section{Edilson Paulo}

Professor do Departamento de Finanças e Contabilidade, Universidade Federal da Paraíba

e.paulo@uol.com.br

\section{Maria Thereza Pompa Antunes}

Professora do Programa de Pós-Graduação em Ciências Contábeis, Universidade Presbiteriana Mackenzie mariathereza@mackenzie.com.br

\section{Henrique Formigoni}

Professor da Faculdade de Ciências Econômicas Contábeis e Administrativas, Universidade Presbiteriana Mackenzie hformigoni@mackenzie.com.br

Recebido em 11.09.2006. Aprovado em 14.04.2008

Avaliado pelo sistema double blind review

Editor Científico: Ricardo Ratner Rochman

\begin{abstract}
The objective of this paper is to identify the existence of significant differences between Brazilian publicly-quoted and private companies as far as concerns the conservative nature of their financial statements. The exploratory and descriptive research was based on a sample of 1,384 company years, with 770 observations relating to private companies and 614 to publicly-quoted companies, for the period 2000 to 2004. The Ball and Shivakumar (2005) model was used, which allows conservatism to be analyzed by means of the reversion of accounting results. The results obtained are evidence that in private companies there is less likelihood of recognizing losses opportunely and because of this their financial statements are less conservative than those of publicly-quoted companies.
\end{abstract}

PALAVRAS-CHAVE Conservadorismo, reconhecimento assimétrico dos resultados, qualidade da informação contábil, companhias abertas e fechadas, mensuração contábil.

KEYWORDS Conservatism, asymmetric recognition of the results, quality of the accounting information, public-quoted and private companies, accounting measurement. 


\section{INTRODUÇÃO}

Sob a ótica da teoria da firma, a Contabilidade contribui com os mecanismos de governança minimizando o impacto dos conflitos de agência, por meio da redução da assimetria informacional. As pesquisas sobre redução de assimetria (HOLTHAUSEN e WATTS, 2001; LOPES, 2002; BALL, KOTHARI e ROBIN, 2000; BALL e SHIVAKUMAR, 2005; PAULO, 2007) buscam analisar a qualidade da mensuração contábil, cujas métricas possuem aspectos subjetivos. O regime de competência (accrual basis) e outros conceitos contábeis mudam conforme a estrutura institucional na qual a firma está inserida. Fatores como o sistema de governança, a auditoria, a regulação contábil e os sistemas de normas, o enforcement e as relações jurídicas dos contratos e investidores são variantes do contexto econômico organizacional.

Uma das principais características da qualidade das informações contábeis, também de natureza subjetiva, é o conservadorismo, inserido na maioria das estruturas conceituais de contabilidade. Pesquisadores na área de Finanças e Contabilidade realizaram diversos trabalhos, nos últimos anos, para analisar empiricamente o nível de conservadorismo nos sistemas contábeis de diferentes países (BASU, 1997; AHMED, MORTON e SCHAEFER, 2000; BALL, KOTHARI e ROBIN, 2000; BALL e SHIVAKUMAR, 2005).

Esses estudos comumente conceituam o conservadorismo como o reconhecimento enviesado das más notícias mais rapidamente do que das boas notícias, ou seja, a contabilidade tem maior tendência de reconhecer uma despesa (ou perda) do que uma receita (ou ganho). Têmse como exemplos de práticas conservadoras:

a) a mensuração baseada no custo não reconhece o incremento de valor, mas as normas requerem impairment no caso de declínio (conceito de custo ou mercado, dos dois o menor);

b) o não reconhecimento de muitos ativos intangíveis e, se reconhecidos, sua avaliação pelos mesmos critérios de mensuração e evidenciação dos ativos tangíveis e não pelos seus potenciais benefícios futuros;

c) o registro das perdas esperadas quando elas se tornam conhecidas, enquanto os ganhos não são reconhecidos enquanto não forem realizados;

d) a atribuição de maior peso às estimativas de perdas nos casos de dúvida.

Em síntese, o conservadorismo é uma prática de reconhecimento assimétrico, que privilegia o critério contábil com o menor ativo/receita ou maior passivo/ despesa. No caso de um reconhecimento simétrico das boas e más noticias, não existe o conservadorismo (prudência). Adicionalmente, tem-se que o comportamento conservador não ocorre nos casos em que as boas notícias são reconhecidas mais rapidamente do que as más notícias.

Assim como as demais características da informação contábil, o conservadorismo também sofre influência direta do sistema regulatório, da dinâmica do mercado de capitais de cada país e do tipo de sociedade empresarial. Observa-se que as pesquisas empíricas nacionais e internacionais sobre o tema têm-se concentrado nas companhias abertas (BALL e SHIVAKUMAR, 2005; PAULO, 2007).

No Brasil, verifica-se que os procedimentos e práticas contábeis adotados pelas companhias fechadas e pelas abertas são, em grande parte, semelhantes, uma vez que têm como diretriz principal a Lei $n^{\circ}$ 6.404/76 (Lei das Sociedades Anônimas).

Especificamente em relação à divulgação das informações ao mercado, a legislação brasileira prevê para ambos os tipos de sociedade a publicação, pelo menos anualmente, de suas demonstrações contábeis, não obstante o mercado normalmente exigir maior qualidade e conteúdo informacional dos relatórios contábeis divulgados pelas companhias abertas. Isso se deve ao fato de que as sociedades abertas devem atender às exigências específicas da Comissão de Valores Mobiliários (CVM) e das práticas de governança corporativa.

No Brasil, as companhias fechadas são de grande importância para a economia local. Com base nos rankings da revista Exame - Melhores e Maiores publicados nos anos de 2001 a 2005, verifica-se que a soma das receitas brutas das companhias fechadas representa, em média, 40\% da receita bruta total das 500 maiores empresas, nesse período. Entende-se, portanto, que sejam de grande relevância para o contexto econômico e social brasileiro estudos que tenham como foco as sociedades anônimas de capital fechado. Isso se justifica, por um lado, pela magnitude de seu faturamento no rol das grandes empresas nacionais e, por outro, como sugerem Iudícibus e Lopes (2004), para que os efeitos dos conceitos contábeis no contexto organizacional e nos mecanismos de governança dessas empresas possam ser testados por pesquisadores. Adicionalmente, Lopes (2002) ressalta que o conservadorismo e seu impacto no conteúdo informativo da contabilidade são temas que ainda carecem de estudos.

O breve cenário exposto leva-nos a questionar de que maneira os números contábeis são influenciados pelo conservadorismo, dependendo do tipo de sociedade anônima 
das companhias brasileiras. Isto é, os números contábeis das S/As diferem entre si, em maior ou menor grau de conservadorismo, devido à natureza (aberta ou fechada) dessas empresas?

Objetiva-se, assim, verificar, comparativamente entre companhias abertas e fechadas brasileiras, as diferenças significativas existentes nos níveis de conservadorismo de suas demonstrações contábeis. Para isso, desenvolveu-se uma pesquisa exploratória e descritiva, aplicando-se o modelo econométrico proposto por Ball e Shivakumar (2005) a uma amostra composta por 1.384 empresas-ano.

Formalmente, o estudo é composto por três partes. Inicialmente, faz-se uma breve revisão dos aspectos que diferenciam as companhias abertas das fechadas. Em seguida, apresentam-se os procedimentos metodológicos adotados na pesquisa, e, na seção seguinte, os resultados são descritos e analisados. Finalizando o estudo, formulam-se algumas considerações sobre os resultados apurados. Este trabalho pretende contribuir para uma melhor compreensão de como as empresas abertas e fechadas brasileiras se posicionam quanto ao conservadorismo contábil.

\section{PROCEDIMENTOS METODOLÓGICOS}

A discussão dos procedimentos metodológicos está organizada em três subseções: tipo e método de pesquisa, seleção e composição da amostra, e desenvolvimento da hipótese.

\section{Tipo e método de pesquisa}

Este estudo caracteriza-se como uma pesquisa exploratória e descritiva (KÖCHE, 1999; CERVO e BERVIAN, 2002). Exploratória, pois se buscou a obtenção de maiores conhecimentos sobre o conservadorismo no âmbito das sociedades anônimas no mercado brasileiro. Descritiva, pois se procurou verificar, quantitativamente, as diferenças entre os níveis de conservadorismo praticados pelas companhias abertas e fechadas brasileiras.

\section{Seleção e composição da amostra}

A amostra inicial deste estudo foi composta pelas sociedades anônimas de capital aberto e de capital fechado e extraída do ranking das 500 maiores empresas em operação no Brasil, classificadas pelo volume de vendas, no período de 2000 a 2004, segundo a revista Exame Melhores e Maiores.
Os dados das companhias abertas foram obtidos junto aos bancos de dados disponibilizados pela Comissão de Valores Mobiliários (CVM) e pela Economática. Já os das companhias fechadas vieram do banco de dados da Fundação Instituto de Pesquisas Contábeis, Atuariais e Financeiras (Fipecafi).

No período de 2000 a 2004, foram identificadas 723 empresas (excluídas as repetições); dessas, 234 eram sociedades por cota de responsabilidade limitada e sociedades cooperativas, que foram excluídas da amostra. Restaram, portanto, 489 empresas constituídas na forma de sociedades anônimas, das quais 343 companhias fechadas (70\%) e 146 companhias abertas (30\%), perfazendo um total de 2.445 empresas-ano.

As sociedades abertas que efetuaram a primeira oferta pública de ações durante o período compreendido neste estudo, ou seja, passaram de companhia fechada para companhia aberta, foram excluídas no ano em que esse fato ocorreu, a fim de se evitar a possibilidade de viés amostral (GREENE, 2003). Além disso, foram excluídas as companhias nos períodos em que passaram pelo processo contrário, ou seja, fecharam o capital social da empresa. Descartadas ainda as observações incompletas, a amostra final foi composta por 1.384 empresas-ano (770 empresas-ano referentes às companhias fechadas e 614 empresas-ano referentes às companhias abertas.

\section{Desenvolvimento da hipótese}

Considerando-se o conservadorismo na Contabilidade e a importância de se compreender as diferenças entre as características da informação contábil nos diversos ambientes institucionais, em particular, no âmbito das companhias abertas e fechadas brasileiras, adotou-se a seguinte hipótese de pesquisa:

Hipótese: O nível de conservadorismo nas demonstrações contábeis das companhias fechadas é significativamente menor do que o contido nas demonstrações contábeis das companhias abertas brasileiras.

Em função da possibilidade de serem aplicados tanto às companhias abertas como às fechadas-diferentemente dos demais modelos existentes na literatura corrente -, para analisar o nível de conservadorismo foram utilizados os modelos desenvolvidos por Ball e Shivakumar (2005) descritos nas Equações 2 e 3.

Considerando-se a hipótese adotada nesta pesquisa, assumiu-se que o somatório dos coeficientes $\alpha_{2}$ e $\alpha_{3}$, do modelo apresentado na Equação 2, seja maior para as companhias fechadas do que para as abertas, pois espera- 
se que as primeiras tenham menor reversão de resultados negativos. Quando da aplicação do modelo descrito pela Equação 3, espera-se que o coeficiente $\alpha_{7}$ seja maior que 0 , confirmando, assim, que as companhias fechadas têm menor probabilidade de reconhecimento oportuno das perdas. As duas equações foram utilizadas, para propiciar maior robustez estatística às análises do presente estudo.

\section{REFERENCIAL TEÓRICO}

Nesta seção, realiza-se uma breve discussão acerca da preparação dos relatórios contábeis, tendo em vista as possíveis influências sobre a sua elaboração e, conseqüentemente, a qualidade das informações divulgadas. Em seguida, insere-se o conceito de conservadorismo na perspectiva contábil, tendo em vista as suas determinações e as concepções desenvolvidas nesse campo de conhecimento. Finalmente, define-se, quantitativamente, o modelo de conservadorismo a ser testado na pesquisa.

\section{Informação contábil}

Os relatórios contábeis são meios importantes para a administração divulgue a performance da empresa para os investidores (PALEPU, HEALY e BERNARD, 2004). Devem, assim, permitir a análise sobre aspectos de liquidez e solvência, estrutura de capital, administração do capital de giro, política de distribuição de dividendos e, ainda, propiciar a análise do desempenho da empresa e dos administradores, e permitir a previsão de fluxos futuros de caixa.

Com relação à qualidade da informação, Lopes e Martins (2005) observam que ela sofre influência direta dos interesses pessoais dos administradores ou agentes (conforme definição da teoria da agência). Esses interesses podem-se referir a fatores como mecanismos de remuneração, acordos contratuais, legislação societária e concorrência, dentre outros. Além desses, Ball (1999), Ali e Hwang (2000), Sloan (2001) e Giner e Rees (2001) consideram as fontes de financiamento, a legislação tributária e a estrutura acionária como outras possíveis influências sobre a qualidade da informação. Ademais, Pope e Walker (1999) associam as diferenças no conteúdo informacional às características institucionais e ao mercado de capitais. Todos esses fatores implicam a possibilidade de existirem informações contábeis enviesadas.

Adicionalmente, a informação contábil sofre influência da existência de critérios múltiplos nas normas e práticas contábeis. Isso possibilita aos administradores escolhe- rem alternativas válidas com o objetivo de apresentarem informações da forma desejada, impactando o desempenho ou a estrutura financeira da empresa (FIELDS, LYS e VICENT, 2001; FRANCIS, 2001).

Fields, Lys e Vicent (2001) descrevem que a natureza das escolhas contábeis inclui:

- escolha entre regras igualmente aceitas;

- julgamentos e estimativas requeridas por alguns sistemas contábeis;

- decisões de estratégias de disclosure;

- decisões do momento do reconhecimento; e

- atividades de lobby.

O conceito de escolhas contábeis incorpora, portanto, um amplo conjunto de atividades que afetam os números contábeis. Cabe ressaltar que, enquanto algumas escolhas têm efeitos imediatos e/ou de longo prazo nos resultados, outras afetam somente os componentes dos resultados período a período.

A estrutura societária da empresa também pode afetar a qualidade da informação contábil. A esse respeito, Ball e Shivakumar (2005) mostram que as companhias fechadas apresentam maior tendência para resolver seus problemas de assimetria informacional internamente do que as companhias abertas.

Com relação ao aspecto da divulgação das informações contábeis no Brasil, as companhias fechadas e as abertas têm, basicamente, as mesmas obrigações. A Lei das Sociedades Anônimas (LSA) determina que as sociedades anônimas publiquem, anualmente, o relatório da administração, as demonstrações financeiras, a convocação das assembléias e outros documentos. No caso das sociedades de capital aberto, a CVM determina, ainda, a apresentação periódica das demonstrações financeiras, informações anuais e informações trimestrais, assim como, extemporaneamente, quaisquer informações relevantes a respeito dos seus negócios (Instrução CVM n' 202/93).

Dentre as principais dimensões da qualidade da informação contábil, destacam-se o conservadorismo e a oportunidade. O conservadorismo implica decisões sobre o momento do reconhecimento oportuno dos ganhos e das perdas, influenciando, assim, a escolha contábil. O conceito de oportunidade, por sua vez, está ligado à "velocidade" com que o lucro contábil incorpora o retorno econômico em um determinado período. Esse fato é influenciado pelos fatores institucionais das empresas, tais como, o sistema de governança e o sistema normativo de contabilidade (BALL, KOTHARI e ROBIN, 2000). 


\section{Conservadorismo}

O conservadorismo, segundo Lopes (2002), é uma das características mais importantes do corpo de práticas e procedimentos da contabilidade e está presente na maioria das estruturas conceituais, como nas emitidas pelo Financial Accounting Standard Board (FASB), International Accounting Standard Board (IASB) e Accounting Standard Board (ASB), e pelo modelo normativo brasileiro.

Em termos contábeis, a convenção do conservadorismo estabelece que, entre possibilidades alternativas de avaliação do patrimônio, deve-se escolher aquela que represente o menor valor atual para o ativo/receita e o maior valor para o passivo/despesa. Portanto, trata-se de um reconhecimento assimétrico entre o ativo/receita e o passivo/despesa, devendo ser considerado o cenário menos favorável. Do ponto de vista econômico, significa o reconhecimento enviesado da realidade econômica (BASU, 1997).

Basu (1997, p. 3) explica que o conservadorismo é o resultado que reflete as más notícias (bad news) mais rapidamente do que as boas notícias (good news), levando às "diferenças sistemáticas entre os períodos das más notícias e das boas notícias no momento oportuno (timeless) e na persistência dos resultados".

Para Watts (2003a), uma das conseqüências do conservadorismo é a persistência da subestimação dos valores do ativo líquido (ativo total menos passivo total). Em certo ponto, o autor considera que o conservadorismo refere-se aos efeitos financeiros acumulados no balanço patrimonial e para os resultados acumulados desde o inicio de suas operações, pois apresenta uma subavaliação sistemática dos saldos evidenciados nas demonstrações contábeis, o que implica que a prática conservadora não possui conseqüências de mensuração somente no período em que ocorre o reconhecimento contábil.

Com relação ao efeito do comportamento conservador na contabilidade, verifica-se que não existe um consenso sobre a verdadeira utilidade proporcionada por essa prática. Hendriksen e Breda (1999), ao criticarem a utilização do conservadorismo, enfatizam que a não existência de um padrão uniforme para sua utilização prejudica a comparabilidade dos números contábeis. Adicionalmente, Holthausen e Watts (2001) consideram que as estimativas contábeis não verificáveis dão margem a comportamento discricionário, ou seja, oportunístico por parte dos gestores. Por outro lado, Lopes (2002) considera que a idéia geral do conservadorismo é a de fornecer informações mais confiáveis aos investidores por intermédio de demonstrações que não sejam excessi- vamente otimistas. Além disso, Watts (2003a), buscando fatores que expliquem a existência do reconhecimento assimétrico, entende que o conservadorismo está fortemente vinculado às relações contratuais entre a firma e seus credores, com o intuito de possibilitar garantias mínimas para o cumprimento das obrigações. Para esse autor, o conservadorismo, em termos de contrato, eleva o valor da firma, porque restringe o comportamento oportunístico dos administradores, em benefício próprio ou de outros interessados. Considera, portanto, que o conservadorismo é um mecanismo eficiente na determinação dos parâmetros contratuais.

É de se ressaltar que, não havendo restrições à prática do comportamento oportunístico, os números contábeis que aparentemente se mostram neutros seriam significativamente enviesados. O conservadorismo, nesse caso, pode contribuir para minimizar a influência do comportamento oportunístico dos administradores sobre os relatórios contábeis que servem como referência para os contratos, contrapondo-se ao viés do administrador por meio da exigência assimétrica da verificabilidade. Em suma, as práticas contábeis são mais exigentes com o nível de verificação das boas notícias do que das más notícias (WATTS, 2003a).

Outro aspecto analisado por Watts (2003a) é o da tributação, pois considera que ela tem forte influência sobre a prática do conservadorismo, na medida em que as empresas lucrativas podem reduzir o desembolso tributário por meio da postergação das receitas e aceleração das despesas. Shackelford e Shevlin (2001) explicam que um maior vínculo da tributação com os relatórios contábeis torna a contabilidade mais conservadora.

Nesse contexto, a verificabilidade tem papel importante no processo contábil, principalmente quando relacionada aos aspectos legais, pois contratos baseados em números contábeis não verificáveis dificilmente podem ser exigidos e contestados nos âmbitos legais e administrativos. Da mesma forma, a caracterização de fraude tributária, ou contábil, requer a verificação dos números contábeis.

Em síntese, os números contábeis podem ser verificados, mas existem situações, ou eventos, em que isso não ocorre. Por exemplo, a subjetividade envolvida no cálculo do retorno esperado dos investimentos em pesquisa e desenvolvimento faz com que o processo de mensuração contábil se apóie em uma série de pressupostos econômicos, freqüentemente não aceitos por todos os experts.

Embora se considere que a forma ideal para a mensuração contábil dos eventos e transações da empresa deva 
incluir os fluxos futuros de caixa das ações correntes da administração, a falta de comprovação (verificabilidade) faz com que, normalmente, esses fluxos não sejam incorporados nos arranjos contratuais.

Outro aspecto relacionado com o conservadorismo, segundo Watts (2003a), é o sistema regulatório da contabilidade. Pode-se verificar que os organismos responsáveis pelo sistema normativo contábil de vários países e o IASB estabelecem padrões inconsistentes com os propósitos do conservadorismo. Por exemplo, no Statement $\mathrm{n}^{\circ} 142$ Goodwill and Other Intangible Assets, o FASB (2001) estabelece a amortização do goodwill por meio de impairment, conceito esse que necessita da avaliação dos fluxos futuros de caixa não verificáveis. Esse fato reflete bem a dicotomia entre a prática do conservadorismo e a neutralidade apregoada pelos responsáveis pela regulamentação contábil. Watts (2003b) alerta para o fato de que os reguladores do sistema contábil buscam eliminar o conservadorismo sem o devido entendimento dos seus benefícios, e, dessa forma, as normas contábeis resultantes podem, provavelmente, prejudicar os objetivos dos relatórios contábeis.

Lara e Mora (2004) indicam dois modelos de avaliação das práticas de conservadorismo: o conservadorismo baseado nos Resultados (Earnings Conservatism) e o conservadorismo baseado no Balanço Patrimonial (Balance Sheet Conservatism). O primeiro é caracterizado pela existência de uma subavaliação persistente do valor patrimonial em relação ao valor de mercado da firma (LARA e MORA, 2004). Nessa linha, Givoly e Hayn (2000) utilizaram o índice market-to-book como proxy para o conservadorismo baseado no Balanço Patrimonial, indicando que esse índice será sempre maior que 1 quando da existência de práticas conservadoras. Por sua vez, o conservadorismo baseado nos Resultados está respaldado no pressuposto de que o conservadorismo é uma conseqüência temporal dos ganhos e perdas relacionados aos fluxos de caixas correspondentes (LARA e MORA, 2004). Nessa abordagem, a prática conservadora foca na subavaliação dos resultados contábeis (BASU, 1997; POPE e WALKER, 1999). Basu (1997) estudou a assimetria e a oportunidade da incorporação das boas e más notícias aos resultados contábeis, com base em regressão dos resultados de períodos anteriores.

Embora amplamente utilizados em pesquisas empíricas, esses modelos sofrem críticas por não controlarem o comportamento discricionário dos administradores sobre a mensuração dos accruals, pela utilização da abordagem linear e pela omissão de variáveis relevantes (GYVOLY e HAYN, 2000; WATTS, 2003b;
LARA e MORA, 2004). Ainda em relação às críticas à abordagem econométrica do conservadorismo baseado nos Resultados, Watts (2003b) alerta para o fato de a prática conservadora ser freqüentemente atribuída aos banqueiros e a outras fontes de financiamento que utilizam o Balanço Patrimonial, conforme descrito nos FASB Concepts no 2 (FASB, 1998). Entretanto, Lara e Mora (2004) demonstram que as práticas de Conservadorismo mensuradas pelo modelo empírico baseado no Balanço Patrimonial são estatisticamente semelhantes ao nível de conservadorismo relacionado à abordagem receita/despesa, baseado em Resultados.

\section{Definição do modelo empregado}

Devido à presença do conservadorismo nos números contábeis, há uma tendência de maior persistência dos ganhos do que das perdas. O conservadorismo faz, portanto, com que as acumulações (accruals) sejam assimétricas, visto que as perdas tendem a ser totalmente reconhecidas, ao passo que o mesmo não ocorre com os ganhos. Dessa forma, o período de competência tende a apresentar menor lucro ou evidenciar menor ativo líquido em decorrência da diminuição dos accruals positivos cumulativos.

Basu (1997) afirma que as mudanças de resultados negativos são mais prováveis de se reverter no próximo período do que os resultados positivos. Por outro lado, enquanto os relatórios contábeis só reconhecem, totalmente, no próprio período as más notícias, os preços das ações refletem, a priori, simetricamente as boas e as más notícias. Esse modelo utiliza o conceito fundamental de clean surplus relation, que, segundo Iudícibus e Lopes (2004), implica que o lucro a ser considerado no modelo seja somente aquele que inclui todas as alterações ocorridas no patrimônio líquido em um determinado período, desde que não sejam decorrentes de transações com acionistas.

Um dos modelos mais utilizados na investigação empírica tem sido o proposto por Basu (1997), que pode ser descrito da seguinte forma:

$\frac{X_{i t}}{P_{i t-1}}=\alpha_{0}+\alpha_{1} D R_{i t}+\beta_{0} R_{i t}+\beta_{1} R_{i t}^{*} D R_{i t}+\varepsilon_{i t}$

Em que:

$X_{i t} \quad=$ lucro líquido contábil por ação da empresa $i$ no ano $t$;

$P_{i t-1}=$ preço por ação da empresa $i$ no final do ano $t-1$;

$R_{i t}=$ retorno econômico por ação da empresa $i$ no ano $t$; 
$D R_{i t}=$ variável dummy para indicar se o retorno é negativo; assumindo valor 1 se Rit < 0, e 0 nos demais casos;

$\varepsilon_{i t} \quad=$ erro da regressão.

Esse modelo regride as mudanças de resultados ponderadas pelos preços das ações no início do período, sobre mudanças dos resultados positivos e das mudanças dos resultados negativos. Nesse contexto, o retorno econômico da ação é uma proxy para o resultado econômico, baseado em algum nível de eficiência de mercado. A regressão pode analisar se o resultado contábil incorpora, significativamente, o resultado econômico (significância do coeficiente $\beta_{0}$ ), avaliando, assim, a oportunidade (tempestividade) do seu reconhecimento contábil.

Apesar de amplamente utilizado em pesquisas empíricas, conforme se pode verificar em Basu (1997), Lara e Mora (2004) e Costa e Costa (2005), o modelo descrito na Equação 1 não se aplica aos propósitos do presente estudo, pois necessita de variáveis observáveis no mercado de capitais, o que torna seu uso, a priori, inviável para a análise das companhias fechadas.

Portanto, optou-se pelo modelo desenvolvido por Ball e Shivakumar (2005), que se apresenta aplicável ao contexto das companhias fechadas e abertas, descrito da seguinte forma:

$\Delta N I_{i t}=\alpha_{0}+\alpha_{1} D \Delta N I_{i t-1}+\alpha_{2} \Delta N I_{i t-1}+\alpha_{3} \Delta N I_{i t-1} * D \Delta N I_{i t-1}+\varepsilon_{i t}$

Em que:

$\Delta N I_{i t}=$ variação no lucro líquido contábil da empresa $i$ do ano $t-1$ para o ano $t$ ponderada pelo valor do ativo total no início do ano $t$;

$\Delta \mathrm{NI}_{i t-1}=$ variação no lucro líquido contábil da empresa $i$ do ano $t-2$ para o ano $t-1$ ponderada pelo valor do ativo total no início do ano $t-1$;

$\mathrm{D} \Delta \mathrm{NI}_{\mathrm{it}-1}=$ variável dummy para indicar se existe variação negativa no lucro líquido contábil da empresa $i$ do ano $t-1$ para o ano $t$, assumindo valor 1 se $\Delta \mathrm{NI}_{i t}<$ 0 , e 0 nos demais casos;

$\varepsilon_{i t} \quad=$ erro da regressão.

Nesse modelo (Equação 2), a utilização da "variação no lucro líquido contábil" como variável independente tem a vantagem de fornecer uma especificação adequada para identificar os componentes transitórios do resultado (BALL e SHIVAKUMAR, 2005). A hipótese assumida pelos autores é de que existe menor reversão de decréscimos negativos de resultados nas companhias fechadas do que nas companhias abertas, refletindo uma menor freqüência de reconhecimento oportuno das perdas, devido à menor demanda por comportamento conservador na mensuração das informações contábeis.

Espera-se que o coeficiente $\alpha_{2}$ seja igual a zero $\left(\alpha_{2}=0\right)$, pois o diferimento do reconhecimento dos ganhos até o momento em que seu fluxo de caixa é realizado faz com que os resultados positivos se tornem um componente persistente do lucro contábil, que tende a não ser revertido (BALL e SHIVAKUMAR, 2005). No caso de reconhecimento oportuno, os ganhos passam a ser um componente transitório do resultado e tendem a ser revertidos nos períodos subseqüentes. Isso implica que o coeficiente $\alpha_{2}$ seja menor que zero $\left(\alpha_{2}<0\right)$.

Utilizando-se o mesmo raciocínio, o reconhecimento oportuno das perdas resulta em decréscimos transitórios do resultado e, conseqüentemente, devem ser revertidas nos períodos seguintes, implicando, a priori, que o somatório dos coeficientes $\alpha_{2}$ e $\alpha_{3}$ seja menor que zero. Assim, o reconhecimento mais oportuno das perdas do que dos ganhos faz com que o coeficiente $\alpha_{3}$ seja menor que zero. Ressalta-se que não existe uma predição para os coeficientes lineares (interceptores) $\alpha_{0}$ e $\alpha_{1}$ nesse modelo.

Para identificar se o conservadorismo nos relatórios contábeis diverge entre as companhias fechadas e companhias abertas, Ball e Shivakumar (2005) ampliaram o modelo (Equação 2), incluindo uma variável dummy que capta o comportamento diferenciado do conservadorismo nos números contábeis das companhias fechadas. Os autores descrevem o modelo da seguinte forma:

$$
\begin{aligned}
& \Delta N I_{i t}=\alpha_{0}+\alpha_{1} D \Delta N I_{i t-1}+\alpha_{2} \Delta N I_{i t-1}+\alpha_{3} \Delta N I_{i t-1} * D \Delta N I_{i t-1} \\
& +\alpha_{4} D P R+\alpha_{5} D P R^{*} D \Delta N I_{i t-1}+\alpha_{6} D P R^{*} \Delta N I_{i t-1} \\
& +\alpha_{7} D P R^{*} D \Delta N I_{i t-1} * \Delta N I_{i t-1}+\varepsilon_{i t}
\end{aligned}
$$

Em que:

$\Delta \mathrm{NI}_{i t}=$ variação no lucro líquido contábil da empresa $i$ do ano $t-1$ para o ano $t$, ponderada pelo valor do ativo total no início do ano $t$;

$\Delta N I_{i t-1}=$ variação no lucro líquido contábil da empresa $i$ do ano $t-2$ para o ano $t-1$, ponderada pelo valor do ativo total no início do ano $t-1$;

$D \Delta \mathrm{NI}_{i t-1}=$ variável dummy para indicar se a variação no lucro líquido contábil da empresa $i$ do ano $t-1$ para 
o ano $t$ é negativa; assumindo valor 1 se $\Delta \mathrm{NI}_{i t}<$ 0 , e 0 nos demais casos;

$D P R=$ variável dummy para indicar se a empresa é companhia fechada, assumindo valor 1 se for companhia fechada e valor 0 se for uma companhia aberta; $\varepsilon_{i t} \quad=$ erro da regressão.

De forma semelhante ao modelo anterior (Equação 2), devido ao diferimento do reconhecimento das "boas notícias" (componente positivo persistente do resultado contábil) espera-se que o coeficiente $\alpha_{2}$ seja igual a 0 . Com base no reconhecimento oportuno das "más notícias", tem-se a expectativa de que o coeficiente $\alpha_{3}$ seja menor que zero e que o somatório dos coeficientes $\alpha_{2}$ e $\alpha_{3}$ seja menor que zero.

Entretanto, devido às diferenças das características institucionais e organizacionais, tem-se a hipótese de que as companhias fechadas apresentam menor reconhecimento oportuno das perdas do que as companhias abertas, implicando que o coeficiente $\alpha_{7}$ seja, significativamente, maior que 0 . Ressalta-se, também, que não existe uma predição para os coeficientes lineares (interceptores) $\alpha_{0}, \alpha_{1}, \alpha_{4}$ e $\alpha_{5}$, bem como para o coeficiente $\alpha_{6}$ nesse modelo (Equação 3).

Diante do exposto, este trabalho utilizou uma abordagem empírica por meio da aplicação do modelo econométrico descrito segundo Ball e Shivakumar (2005) de acordo com as Equações 2 e 3.

Todas as análises estatísticas foram realizadas considerando-se um nível de significância de 5\%. Adicionalmente, foram realizados testes com as variáveis de controle para o tamanho da empresa (valor do ativo total no final do período) e auditoria (se a empresa analisada é auditada por uma das quatro grandes empresas mundiais de auditoria assume o valor 1 , caso contrário, igual a 0).

\section{APRESENTAÇÃO E ANÁLISE DOS RESULTADOS}

Os dados da estatística descritiva e do teste de normalidade da variável, "variação no lucro líquido contábil", para companhias fechadas e companhias abertas, encontram-se na Tabela 1. Com o intuito de se verificar a normalidade, utilizou-se o Teste K-S (Kolmogorov-Smirnov). Para o período analisado, pôde-se verificar que existem evidências estatísticas para rejeitar a normalidade das variações de resultados, ou seja, a variável utilizada neste trabalho não segue uma distribuição normal considerando-se um nível de significância de 0,05 (NEWBOLD, CARLSON e THORNE, 2002).

Greene (2003, p. 17) afirma que a normalidade não é necessária para se obterem muitos dos resultados da regressão múltipla, podendo esse pressuposto ser relaxado. Com base no teorema do limite central, Wooldridge (2002, p. 167) afirma que os estimadores do método dos Mínimos Quadrados Ordinários (MQO) satisfazem a normalidade assintótica, ou seja, eles aproximadamente têm distribuição normal em amostras de tamanhos suficientemente grandes. Portanto, os coeficientes da regressão estimados pelo MQO são consistentes e não-enviesados assintoticamente.

A Tabela 2 exibe as estatísticas das regressões crosssectional, calculadas separadamente para as companhias fechadas e as abertas, de acordo com o modelo de conservadorismo proposto pela Equação 2.

Considerando-se um nível de significância de 5\%, verificou-se que o coeficiente $\alpha_{2}$ não é, estatisticamente, diferente de zero (GUJARATI, 2000; WOOLDRIDGE, 2006), nem para as companhias fechadas, nem para as companhias abertas. Assim, confirma-se o que foi predito anteriormente, ou seja, que os resultados positivos se tornam componente persistente do lucro contábil, não sendo revertidos nos períodos subseqüentes nas

Tabela 1 - Estatística descritiva

\begin{tabular}{|c|c|c|}
\hline & COMPANHIAS FECHADAS & COMPANHIAS ABERTAS \\
\hline Média & 0,026 & 0,021 \\
\hline Desvio padrão & 0,154 & 0,162 \\
\hline Kolmogorov-Smirnov & 0,163 & 0,197 \\
\hline Probabilidade & 0,000 & 0,000 \\
\hline Observações & 770 & 714 \\
\hline
\end{tabular}


demonstrações contábeis das sociedades anônimas (fechadas e abertas).

O somatório dos coeficientes $\alpha_{2}$ e $\alpha_{3}$ para as amostras das companhias fechadas e abertas são, respectivamente, $-0,986$ e $-1,440$. Como em ambos os casos esses somatórios são menores que zero $\left(\alpha_{2}+\alpha_{3}<0\right)$, verificou-se que os números oferecem evidências empíricas de reconhecimento oportuno das perdas, sendo essas revertidas nos períodos seguintes. Pode-se também observar na Tabela 2 que, em ambos os casos, o coeficiente $\alpha_{3}$ é significativamente menor que $0\left(\alpha_{3}<0\right)$ (GUJARATI, 2000; WOOLDRIDGE, 2006).

Procedendo-se a uma comparação entre o somatório dos coeficientes $\alpha_{2}$ e $\alpha_{3}$ do modelo apresentado na Equação 2, verificou-se que as companhias fechadas têm, significativamente, uma menor reversão dos resultados negativos $(-0,986)$, em relação às companhias abertas $(-1,440)$. Confirma-se, assim, a hipótese adotada nesta pesquisa, ou seja, que o nível de conservadorismo nos números contábeis das companhias fechadas é menor do que o nível apresentado nos números contábeis das companhias abertas.

Os resultados da regressão cross-sectional do modelo de conservadorismo descrito na Equação 3, conforme Ball e Shivakumar (2005), estão apresentados na Tabela 3.

A análise dos resultados permitiu verificar que o coeficiente $\alpha_{2}$ não é estatisticamente diferente de zero ( $p$-value $>0,05)$, confirmando a expectativa de que os resultados positivos não são revertidos nos períodos subseqüentes, tornando-se componente persistente do resultado contábil. Por outro lado, os resultados negativos são revertidos nos anos posteriores ao seu reconhecimento oportuno, pois o somatório dos coeficientes $\alpha_{2}$ e $\alpha_{3}(-1,440)$ é significativamente menor que zero $\left(\alpha_{2}+\alpha_{3}<0\right)$. Ou seja, existe menor probabilidade de ajustes contábeis nos resultados positivos do que nos negativos, indicando que o reconhecimento de receitas (e ganhos) é efetuado com um maior grau de certeza quando comparado com o reconhecimento das despesas (ou perdas).

Tabela 2 - Regressão de cálculo isolado do conservadorismo - cross-sectional

\begin{tabular}{|c|c|c|c|c|}
\hline & \multicolumn{2}{|c|}{ COMPANHIAS FECHADAS } & \multicolumn{2}{|c|}{ COMPANHIAS ABERTAS } \\
\hline & COEFICIENTE & P-VALUE & COEFICIENTE & P-VALUE \\
\hline Interceptor & 0,009 & 0,161 & 0,004 & 0,611 \\
\hline$D \Delta N I_{i t-1}$ & $-0,029$ & 0,016 & $-0,055$ & 0,000 \\
\hline$\Delta N l_{i t-1}$ & $-0,021$ & 0,663 & 0,103 & 0,174 \\
\hline$\Delta N I_{i t-1} * D \Delta N I_{i t-1}$ & $-0,965$ & 0,000 & $-1,543$ & 0,000 \\
\hline$R^{2}$ & 0,208 & & 0,441 & \\
\hline$R^{2}$ ajustado & 0,204 & & 0,437 & \\
\hline FAnova & 61,319 & 0,000 & 105,863 & 0,000 \\
\hline Observações & 770 & & 614 & \\
\hline
\end{tabular}

Nota: Modelo empregado para investigar separadamente a influência do conservadorismo nos relatórios contábeis das companhias fechadas e abertas brasileiras (Equação 2): $\Delta N I_{i t}=\alpha_{0}+\alpha_{1} D \Delta N I_{i t-1}+\alpha_{2} \Delta N I_{i t-1}+\alpha_{3} \Delta N l_{i t-1^{*}} D \Delta N I_{i t-1}+\varepsilon_{i t}$

$\Delta N I_{i t}=$ variação no lucro líquido contábil da empresa $i$ do ano $t-1$ para 0 ano $t$ ponderada pelo valor do ativo total no início do ano $t$;

$\Delta N I_{i t-1}=$ variação no lucro líquido contábil da empresa $i$ do ano $t-2$ para 0 ano $t-1$ ponderada pelo valor do ativo total no início do ano $t-1$;

$D \Delta N_{i t-1}=$ variável dummy para indicar se a variação no lucro líquido contábil da empresa $i$ do ano t-1 para 0 ano $t$ é negativa; assumindo valor 1 se $\Delta \mathrm{NI}_{i t}<0$, e 0 nos demais casos;

cit $=$ erro da regressão. 
Com relação à hipótese de pesquisa adotada neste estudo, pode-se dizer que esta se confirma, pois o coeficiente $\alpha_{7}$ calculado $(0,578)$ é, significativamente, maior que zero (GUJARATI, 2000; WOOLDRIDGE, 2006), evidenciando que as companhias fechadas apresentam menor reconhecimento oportuno das perdas do que as companhias abertas.

No intuito de apresentar melhores evidências sobre o nível de conservadorismo, os modelos apresentados pelas equações 2 e 3 foram estimados por meio de dados em painel. As tabelas 4 e 5 exibem as estimativas dos parâmetros para a amostra com as companhias fechadas e abertas, respectivamente.
Com base no teste de Chow, o modelo de coeficientes comuns é mais adequado do que o modelo de efeitos fixos $(F=1,010)$ e do que modelo de efeitos aleatórios $(F=0,050)$ para análise do conservadorismo na amostra das companhias fechadas. Para a amostra com as companhias abertas, também, o modelo de coeficientes comuns se apresentou mais adequado para análise do que os modelos de efeitos fixos $(F=0,566)$ e de efeitos aleatórios $(\mathrm{F}=0,000)$.

O mesmo fato ocorre quando da utilização do modelo apresentado pela equação 3 (análise conjunta), pois os testes de Chow apresentam um valor F de 0,786 e 0,045, menor do que o valor tabelado. Portanto, pode-se con-

\section{Tabela 3 - Regressão de cálculo conjunto do conservadorismo - cross-sectional}

\begin{tabular}{|c|c|c|}
\hline & COEFICIENTE & P-VALUE \\
\hline Interceptor & 0,004 & 0,607 \\
\hline$D \Delta N I_{i t-1}$ & $-0,055$ & 0,000 \\
\hline$\Delta N I_{i t-1}$ & 0,103 & 0,156 \\
\hline$\Delta N I_{i t-1} * D \Delta N I_{i t-1}$ & $-1,543$ & 0,000 \\
\hline$D P R$ & 0,004 & 0,657 \\
\hline$D P R * D \Delta N I_{i t-1}$ & 0,026 & 0,163 \\
\hline$D P R * \Delta N l_{i t-1}$ & $-0,124$ & 0,157 \\
\hline$D P R * D \Delta N I_{i t-1} * \Delta N I_{i t-}$ & 0,578 & 0,000 \\
\hline$R^{2}$ & 0,314 & \\
\hline$R^{2}$ ajustado & 0,310 & \\
\hline FAnova & 72,324 & 0,000 \\
\hline Observações & 1.384 & \\
\hline
\end{tabular}

Nota: Modelo empregado para investigar a influência do conservadorismo nos relatórios contábeis das companhias fechadas e abertas brasileiras (Equação 3): $\Delta N l_{i t}=\alpha_{0}+\alpha_{1} D \Delta N I_{i t-1}+\alpha_{2} \Delta N I_{i t-1}+\alpha_{3} \Delta N l_{i t-1 *} D \Delta N I_{i t-1}+\alpha_{4} D P R+\alpha_{5} D P R^{*} D \Delta N I_{i t-1}+\alpha_{6} D P R^{*} \Delta N I_{i t-1}$ $+\alpha_{7} D P R^{*} D \Delta N I_{i t-1 *} \Delta N I_{i t-1}+\varepsilon_{i t}$

$\Delta N I_{i t}=$ variação no lucro líquido contábil da empresa $i$ do ano $t-1$ para 0 ano $t$, ponderada pelo valor do ativo total no início do ano $t$;

$\Delta N I_{i t-1}=$ variação no lucro líquido contábil da empresa $i$ do ano $t-2$ para 0 ano $t-1$, ponderada pelo valor do ativo total no início do ano $t-1$;

$D \Delta N_{i t-1}=$ variável dummy para indicar se a variação no lucro líquido contábil da empresa $i$ do ano t-1 para 0 ano $t$ é negativa; assumindo valor 1 se $\Delta \mathrm{NI}_{i t<0}$, e 0 nos demais casos;

$D P R=$ variável dummy para indicar se a empresa é companhia fechada, assumindo valor 1 se for companhia fechada e valor 0 se for companhia aberta;

$\varepsilon_{i t}=$ erro da regressão. 
siderar que para a amostra utilizada neste trabalho não existem efeitos fixos ou aleatórios na análise do nível de conservadorismo, confirmando-se as evidências apresentadas pela regressão estimadas em abordagem cross-sectional. Ressalte-se que, embora os testes Breush-Pagan e Hausman sejam considerados mais robustos para a análise de dados em painel, a utilização do teste de Chow neste estudo não comprometeu os resultados, visto que esses são semelhantes aos obtidos em cross-sectional.

Adicionalmente, verificou-se que as variáveis de controle utilizadas não se apresentaram significativas para análise de dados em nenhuma dos modelos empregados.

\section{CONSIDERAÇÕES FINAIS}

Este estudo buscou evidências empíricas que pudessem contribuir para a reflexão e discussão sobre a qualidade dos números contábeis, por meio da compreensão dos fatores institucionais que influenciam as demonstrações contábeis e a tomada de decisão dos agentes econômicos. Especificamente, este trabalho abordou a prática do conservadorismo nas demonstrações contábeis das companhias abertas e fechadas brasileiras.

A compreensão do comportamento do conservadorismo nos relatórios contábeis é tida como de extrema importância, pois auxilia a análise econômica e financeira das empresas, contribuindo, principalmente, para a alocação dos recursos financeiros, para o estabelecimento das relações contratuais e para o processo regulatório da contabilidade. A literatura internacional, conforme exposto nas seções anteriores, apresenta evidências empíricas de que os resultados positivos se tornam um componente persistente do resultado contábil e, conseqüentemente, não são revertidos nos períodos subseqüentes. Por outro lado, essas pesquisas apontam que os resultados negativos são revertidos em períodos posteriores ao seu reconhecimento oportuno.

Apesar da relevância econômica das companhias fe-

Tabela 4 - Regressão de cálculo do conservadorismo para companhias fechadas - painel

\begin{tabular}{|c|c|c|c|c|c|c|}
\hline & \multicolumn{2}{|c|}{ COEFICIENTES COMUNS } & \multicolumn{2}{|c|}{ EFEITOS FIXOS } & \multicolumn{2}{|c|}{ EFEITOS ALEATÓRIOS } \\
\hline & COEFICIENTE & P-VALUE & COEFICIENTE & P-VALUE & COEFICIENTE & P-VALUE \\
\hline Interceptor & 0,009 & 0,161 & & & 0,009 & 0,158 \\
\hline$D \Delta N I_{i t-1}$ & $-0,029$ & 0,016 & $-0,225$ & 0,001 & $-0,034$ & 0,490 \\
\hline$\Delta N I_{i t-1}$ & $-0,021$ & 0,663 & $-0,032$ & 0,023 & $-0,029$ & 0,015 \\
\hline$\Delta N l_{i t-1} * D \Delta N l_{i t-1}$ & $-0,965$ & 0,000 & $-0,963$ & 0,000 & $-0,968$ & 0,000 \\
\hline$R^{2}$ & 0,208 & & 0,491 & & 0,228 & \\
\hline$R^{2}$ ajustado & 0,204 & & 0,206 & & 0,225 & \\
\hline Sum squared resid & 61,319 & 0,000 & 6,539 & & 9,910 & \\
\hline Observações & 770 & & 770 & & 700 & \\
\hline
\end{tabular}

Nota: Modelo empregado para investigar separadamente a influência do conservadorismo nos relatórios contábeis das companhias fechadas e abertas brasileiras (Equação 2): $\Delta N I_{i t}=\alpha_{0}+\alpha_{1} D \Delta N l_{i t-1}+\alpha_{2} \Delta N l_{i t-1}+\alpha_{3} \Delta N l_{i t-1 *} D \Delta N l_{i t-1}+\varepsilon_{i t *}$

$\Delta N I_{i t}=$ variação no lucro líquido contábil da empresa $i$ do ano $t-1$ para 0 ano $t$ ponderada pelo valor do ativo total no início do ano $t$;

$\Delta N I_{i t-1}=$ variação no lucro líquido contábil da empresa $i$ do ano $t-2$ para 0 ano $t$-1 ponderada pelo valor do ativo total no início do ano $t-1$;

$D \Delta N_{i t-1}=$ variável dummy para indicar se a variação no lucro líquido contábil da empresa $i$ do ano $t-1$ para 0 ano $t$ é negativa; assumindo valor 1 se $\Delta \mathrm{NI}_{i t<0}$, e 0 nos demais casos;

$\varepsilon_{i t}=$ erro da regressão. 
chadas para a economia em diversos países e, em particular, para a economia brasileira, pode-se verificar que as pesquisas empíricas que versam sobre as características da qualidade da informação contábil dessas empresas são reduzidas.

A análise dos dados forneceu evidências empíricas estatisticamente significativas de que os resultados positivos são componentes persistentes dos lucros. Da mesma forma, pôde-se verificar que os resultados negativos são reconhecidos oportunamente, observando-se, assim, um comportamento conservador dos números contábeis apresentados nas demonstrações financeiras, tanto para companhias fechadas, quanto para as companhias abertas.

Os resultados obtidos permitem, portanto, aceitar como válida a hipótese assumida nesta pesquisa, tendo em vista que as companhias fechadas apresentaram menor reconhecimento oportuno das perdas e, conseqüentemente, possuem menor nível de conservadorismo nas demonstrações contábeis do que as companhias abertas.
Uma possível explicação para esse resultado pode residir na existência de maior monitoramento das companhias abertas por parte dos agentes econômicos, tais como auditores, analistas financeiros, órgão reguladores. Outra explicação pode estar no fato de que as normas contábeis estabelecidas pelos órgãos reguladores para as companhias abertas são mais rigorosas em termos de reconhecimento das boas notícias em relação à prática contábil do que para as companhias fechadas.

Diante dos resultados apresentados e considerando as diferenças das características institucionais e organizacionais entre as companhias fechadas e abertas, bem como a relevância econômica desses dois tipos de sociedades, entende-se que a divergência da prática conservadora entre elas deve ser considerada pelos agentes econômicos em suas decisões. Assim sendo, os investidores, as instituições financeiras e de crédito e as outras fontes de financiamento das empresas brasileiras devem procurar um melhor entendimento do efeito do conservadorismo sobre os demonstrativos contábeis, antes de

Tabela 5 - Regressão de cálculo do conservadorismo para companhias abertas - painel

\begin{tabular}{|c|c|c|c|c|c|c|}
\hline & \multicolumn{2}{|c|}{ COEFICIENTES COMUNS } & \multicolumn{2}{|c|}{ EFEITOS FIXOS } & \multicolumn{2}{|c|}{ EFEITOS ALEATÓRIOS } \\
\hline & COEFICIENTE & P-VALUE & COEFICIENTE & P-VALUE & COEFICIENTE & P-VALUE \\
\hline Interceptor & 0,004 & 0,611 & & & 0,005 & 0,534 \\
\hline$D \Delta N I_{i t-1}$ & $-0,055$ & 0,000 & 0,263 & 0,004 & 0,092 & 0,205 \\
\hline$\Delta N I_{i t-1}$ & 0,103 & 0,174 & $-0,062$ & 0,001 & $-0,055$ & 0,000 \\
\hline$\Delta N I_{i t-1 *} D \Delta N I_{i t-1}$ & $-1,543$ & 0,000 & $-2,013$ & 0,000 & $-1,508$ & 0,000 \\
\hline$R^{2}$ & 0,441 & & 0,545 & & 0,429 & \\
\hline$R^{2}$ ajustado & 0,437 & & 0,355 & & 0,424 & \\
\hline Sum squared resid & 6,049 & & 4,918 & & 6,180 & \\
\hline Observações & & & & & & \\
\hline
\end{tabular}

Nota: Modelo empregado para investigar separadamente a influência do conservadorismo nos relatórios contábeis das companhias fechadas e abertas brasileiras (Equação 2): $\Delta N I_{i t}=\alpha_{0}+\alpha_{1} D \Delta N l_{i t-1}+\alpha_{2} \Delta N I_{i t-1}+\alpha_{3} \Delta N I_{i t-1 *} D \Delta N I_{i t-1}+\varepsilon_{i t *}$

$\Delta N I_{i t}=$ variação no lucro líquido contábil da empresa $i$ do ano $t-1$ para 0 ano $t$ ponderada pelo valor do ativo total no início do ano $t$;

$\Delta N I_{i t-1}=$ variação no lucro líquido contábil da empresa $i$ do ano $t-2$ para 0 ano $t-1$ ponderada pelo valor do ativo total no início do ano $t-1$;

$D \Delta N I_{i t-1}=$ variável dummy para indicar se a variação no lucro líquido contábil da empresa $i$ do ano $t-1$ para 0 ano $t$ é negativa; assumindo valor 1 se $\Delta \mathrm{NI}_{i t<0}$, e 0 nos demais casos;

$\varepsilon_{i t}=$ erro da regressão. 
estabelecerem algum tipo de relação contratual, pois tal fato afeta a decisão de alocação dos recursos.

Os organismos responsáveis pela normatização contábil, por sua vez, devem avaliar o impacto das práticas conservadoras sobre as demonstrações contábeis ao emitirem uma nova norma (ou revisão de norma), visto que, conforme demonstrado, o tipo de sociedade receberá e reagirá de forma diferenciada a essa norma.

Em síntese, pode-se verificar que, conforme exposto na literatura, a informação contábil sofre influência do ambiente empresarial e regulatório onde a organização está inserida. Dessa forma, aos agentes econômicos resta entender os efeitos das variáveis envolvidas nos ambientes econômicos em que atuam, pois, dessa forma, podem minimizar o viés informacional nas relações contratuais.

Nesse sentido, com o intuito de contribuir para a ampliação das pesquisas empíricas sobre as características da informação contábil para usuários externos, sugerese que os novos estudos analisem a qualidade dos números contábeis para outros tipos de sociedades, como, por exemplo, as sociedades por cotas de responsabilidade limitada. Além disso, seria interessante o desenvolvimento de modelos econométricos que levassem em consideração as características da economia brasileira.

Tabela 6 - Regressão de cálculo conjunto do conservadorismo - painel

\begin{tabular}{|c|c|c|c|c|c|c|}
\hline & \multicolumn{2}{|c|}{ COEFICIENTES COMUNS } & \multicolumn{2}{|c|}{ EFEITOS FIXOS } & \multicolumn{2}{|c|}{ EFEITOS ALEATÓRIOS } \\
\hline & COEFICIENTE & P-VALUE & COEFICIENTE & P-VALUE & COEFICIENTE & P-VALUE \\
\hline Interceptor & 0,004 & 0,607 & & & 0,003 & 0,700 \\
\hline$D \Delta N I_{i t-1}$ & $-0,055$ & 0,000 & 0,351 & 0,000 & 0,114 & 0,114 \\
\hline$\Delta N I_{i t-1}$ & 0,103 & 0,156 & $-0,057$ & 0,001 & $-0,056$ & 0,000 \\
\hline$\Delta N I_{i t-1 *} D \Delta N I_{i t-1}$ & $-1,543$ & 0,000 & $-2,151$ & 0,000 & $-1,575$ & 0,000 \\
\hline$D P R$ & 0,004 & 0,657 & 0,034 & 0,082 & 0,006 & 0,584 \\
\hline$D P R * D \Delta N I_{i t-1}$ & 0,026 & 0,163 & 0,022 & 0,341 & 0,026 & 0,168 \\
\hline$D P R * \Delta N I_{i t-1}$ & $-0,124$ & 0,157 & $-0,480$ & 0,000 & $-0,145$ & 0,098 \\
\hline$D P R * D \Delta N I_{i t-1} * \Delta N I_{i t-}$ & 0,578 & 0,000 & 1,026 & 0,000 & 0,602 & 0,000 \\
\hline$R^{2}$ & 0,314 & & 0,517 & & 0,330 & \\
\hline$R^{2}$ ajustado & 0,310 & & 0,252 & & 0,326 & \\
\hline Sum squared resid & 16,225 & & 11,437 & & 15,497 & \\
\hline Observações & 1.384 & & 1.384 & & 1.384 & \\
\hline
\end{tabular}

Nota: Modelo empregado para investigar a influência do conservadorismo nos relatórios contábeis das companhias fechadas e abertas brasileiras (Equação 3): $\Delta N I_{i t}=\alpha_{0}+\alpha_{1} D \Delta N l_{i t-1}+\alpha_{2} \Delta N I_{i t-1}+\alpha_{3} \Delta N l_{i t-1 *} D \Delta N I_{i t-1}+\alpha_{4} D P R+\alpha_{5} D P R^{*} D \Delta N l_{i t-1}+\alpha_{6} D P R^{*} \Delta N I_{i t-1}$ $+\alpha_{7} D P R^{*} D \Delta N I_{i t-1} \Delta N I_{i t-1}+\varepsilon_{i t}$

$\Delta N I_{i t}=$ variação no lucro líquido contábil da empresa $i$ do ano $t-1$ para o ano $t$, ponderada pelo valor do ativo total no início do ano $t$ $\Delta N I_{i t-1}=$ variação no lucro líquido contábil da empresa $i$ do ano t-2 para 0 ano $t-1$, ponderada pelo valor do ativo total no início do ano $t-1$;

$D \Delta N I_{i t-1}=$ variável dummy para indicar se a variação no lucro líquido contábil da empresa $i$ do ano t-1 para 0 ano $t$ é negativa; assumindo valor 1 se $\Delta \mathrm{NI}_{i t<0}$, e 0 nos demais casos;

$D P R=$ variável dummy para indicar se a empresa é companhia fechada, assumindo valor 1 se for companhia fechada e valor 0 se for companhia aberta;

$\varepsilon_{i t}=$ erro da regressão. 
EDILSON PAULO - MARIA THEREZA POMPA ANTUNES - HENRIQUE FORMIGONI

\section{REFERÊNCIAS}

AHMED, A. S.; MORTON, R. M.; SCHAEFER, T. F. Accounting conservatism and the valuation of accounting numbers: evidence on the FelthamOhlson (1996) model. Journal of Accounting, Auditing and Finance, v. 15, n. 3, p. 271-292, 2000

ALI, A.; HWANG, L. S. Country-specific factors related to financial reporting and the value relevance of accounting data. Journal of Accounting Research, v. 38, n. 1, p. 1-21, 2000.

BALL, R. Discussion: the association between firms' value and accounting numbers after adoption of fresh start reporting. Journal of Accounting, Auditing and Finance, v. 14, n. 3, p. 212-218, 1999.

BALL, R.; KOTHARI, S. P.; ROBIN, A. The effect of international institutional factors on properties of accounting earnings. Journal of Accounting and Economics, v. 29, n. 1, p. 1-51, 2000.

BALL, Ray; SHIVAKUMAR, Lakshmanan. Earnings quality UK private firms: comparative loss recognition timeliness. Journal of Accounting and Economics, v. 39, n. 1, p. 83-128, 2005

BASU, S. The conservatism principle and the asymmetric timeliness of earnings. Journal of Accounting and Economics, v. 24, n. 1, p. 3-37, 1997.

BRASIL. Lei Federal $n^{\circ}$ 6404. Lei das Sociedades Anônimas. Brasília: Congresso Nacional, 1976.

BUSHMAN, R. M.; SMITH, A. J. Financial accounting information and corporate governance. Journal of Accounting and Economics, v. 31, n. 1-3, p. 237-333, 2001.

CERVO, A. L.; BERVIAN, P. A. Metodologia científica. 5. ed. São Paulo: Prentice Hall, 2002

COMISSÃO VALORES MOBILIARIOS. Instrução normativa $n .^{\circ} 202$ Brasília: CVM, 1993.

COSTA, A. C. O.; COSTA, F. M. Um estudo da aplicação do conservadorismo em cinco países da América do Sul. In: ENCONTRO DA ASSOCIAÇÃO NACIONAL DE PÓS-GRADUAÇÃO E PESQUISA EM ADMINISTRAÇÃO, 29², 2005, Brasília. Anais XXIX Brasília: ANPAD, 2005. 1 CD-ROM

EXAME. Melhores e Maiores. EXAME: São Paulo, jul. 2001. Edição especial.

EXAME. Melhores e Maiores. EXAME: São Paulo, jul. 2002. Edição especial.

EXAME. Melhores e Maiores. EXAME: São Paulo, jul. 2003. Edição especial.
EXAME. Melhores e Maiores. EXAME: São Paulo, jul. 2004. Edição especial.

EXAME. Melhores e Maiores. EXAME: São Paulo, jul. 2005. Edição especial.

FIELDS, T. D.; LYS, T. Z.; VICENT, L. Empirical research on accounting choice. Journal of Accounting and Economics, v. 31. n. 1-3, p. 255-307, 2001 .

FINANCIAL ACCOUNTING STANDARDS BOARD. Statements of Financial Accounting Concepts. New York: John Wiley \& Songs, 1998.

FINANCIAL ACCOUNTING STANDARDS BOARD. Statement $n^{\circ} 142$. Goodwill and Other Intangible Assets. Connecticut: FASB, 2001.

FRANCIS, J. Discussion of empirical research on accounting choice. Journal of Accounting and Economics, v. 31, n. 1-3, p. 309-319, 2001.

FUNDAÇÃO INSTITUTO DE PESQUISAS CONTÁBEIS, ATUARIAIS E FINANCEIRAS. Manual de Contabilidade das sociedades por ações: aplicável às demais sociedades. 6. ed. São Paulo: Atlas, 2003.

GINER, Begoña; REES, William. On the asymmetric recognition of good and bad news in France, Germany and the United Kingdom. Journal of Business Finance and Accounting, v. 28, n. 9-10, nov./dec., p. 1285-1331, 2001.

GIVOLY, D.; HAYN, C. The changing time-series properties of earnings, cash flows and accruals: has financial reporting become more conservative? Journal of Accounting and Economics, v. 29, n. 3, p. 287-320, 2000.

GREENE, W. H. Econometric Analysis. 5. ed. New Jersey: Prentice Hall, 2003.

GUJARATI, D. N. Econometria básica. 3. ed. São Paulo: Pearson, 2000.

HENDRIKSEN, E. S.; BREDA, M. F. V. Teoria da contabilidade. São Paulo: Atlas, 1999.

HOLTHAUSEN, R. W.; WATTS, R. L. The relevance of the value-relevance literature for financial accounting standard setting. Journal of Accounting and Economics, v. 31, n. 1-3, p. 3-75, 2001

IUDÍCIBUS, S.; LOPES, A. B. Teoria avançada da contabilidade. São Paulo: Atlas, 2004.

KÖCHE, J. C. Fundamentos da metodologia científica: teoria da ciência e prática da pesquisa. 15. ed. Petrópolis: Vozes, 1999.

LARA, J. M. G.; MORA, A. Balance sheet versus earnings conservatism in Europe. European Accounting Review, v. 13, n. 2, p. 261-292, 2004.

LOPES, A. B. 2002. A informação contábil e o mercado de capitais. São Paulo: Pioneira Thomson Learning, 2002. 


\section{ARTIGOS - CONSERVADORISMO CONTÁBIL NAS COMPANHIAS ABERTAS E FECHADAS BRASILEIRAS}

LOPES, A. B.; MARTINS, E. Teoria da contabilidade: uma nova abordagem. São Paulo: Atlas, 2005

NEWBOLD, P.; CARLSON, W. L.; THORNE, B. Statistics for Business and Economics. 5. ed. New Jersey: Prentice Hall, 2002.

PALEPU, K. G.; HEALY, P. M.; BERNARD, V. L. Business Analysis Evaluation: Using Financial Statements. 3. ed. Ohio: Thomson Learning, 2004.

PAULO, E. Manipulação das informações contábeis: uma análise teórica e empírica sobre os modelos operacionais de detecção de gerenciamento de resultados. São Paulo, 2007. 455 p. Tese Doutorado em Ciências Contábeis, Programa de Pós-Graduação em Ciências Contábeis, Departamento de Contabilidade e Atuária, Faculdade de Economia, Administração e Contabilidade da Universidade de São Paulo, São Paulo, 2007.

POPE, P. F; WALKER, M. International differences in the timeliness, conservatism, and classification of earnings. Journal of Accounting Research, v. 37, Suppl. n. 1, p. 53-87, 1999.
SHACKELFORD, D. A.; SHEVLIN, T. Empirical tax research in accounting. Journal of Accounting and Economics, v. 31, n. 1-3, p. 321-387, 2001.

SLOAN, R. G. Financial accounting information and corporate governance: a discussion. Journal of Accounting and Economics, v. 31, n. 1-3, p. $335-347,2001$

WATTS, R. L. Conservatism in accounting part I: explanations and implications. Accounting Horizons, v. 17, n. 3, p. 207-221, Sep. 2003a.

WATTS, R. L. Conservatism in accounting part II: evidence and research opportunities. Accounting Horizons, v. 17, n. 4, p. 287-301, Dec. 2003b.

WATTS, R. L.; ZIMMERMAN, J. L. Positive Accounting Theory. New Jersey: Prentice-Hall, 1986.

WOOLDRIDGE, J. M. Introductory econometrics: a modern approach. 2. ed. Ohio: South-Western College Pub., 2002.

WOOLDRIDGE, J. M. Introdução à econometria: uma abordagem moderna. São Paulo: Pioneira Thomson Learning, 2006. 